\title{
K. Heather Pinson, The Jazz Image: Seeing Music Through Herman Leonard's Photography. Jackson, MS: University Press of Mississippi, 2010. 240 pp. ISBN 978-1604734942 (hbk) £29.74.
}

\section{Paul Mclntyre}

Department of Music, Dundalk Institute of Technology, Ireland mcintyremusic@googlemail.com

During the 1980s revival of the Herman Leonard jazz portfolio I bought three prints of his jazz photographs. Because of my ownership of these photographs I found this book enriching and informative in the author's consideration of jazz and jazz culture through Leonard's work. My interest was excited by the investigative contextualization of various cultural issues that the author associates with the topic in a fresh and authoritative approach. The study is extremely broad and uses an interdisciplinary approach to iconography; the author acknowledges this by stating that she has modelled her work on that of Ted Gioia, specifically in relation to his book The Imperfect Art (1988), and in relation to 'society's understanding of the jazz musician as a means to understand the other arts' (p. 12). Structurally, the text is based on a two-part approach: the first two chapters focus on the jazz image, how it is constructed around the AfricanAmerican male jazz musician and aligned with musical classicism and neoclassicism. In the second part, the final two chapters investigate how that neoclassical jazz image is mediated today and how it is highlighted recursively through experimental jazz styles.

Focusing mainly on Leonard's photographs-the majority of which were taken between 1945 and 1959-the author discusses both photographic practices and technical developments early on in the text. This focus also sets the cultural scene for the place of photography during this fifteen-year period and establishes a point of departure for the consideration of jazz as an American art form, through numerous theoretical and contextual portals, and the framing of the African-American jazz musician, mediated almost exclusively as the image of jazz. The most prominent of these contextual portals is the refraction of socio-musical issues through the lens of jazz. The overarching cultural approach sustains the 
interrogation of issues that one may not immediately consider relevant to photography, such as musical genres and styles, jazz in American and other cultures, social constructivism and the black and white communities' struggle for ownership of jazz. Each of these attendant issues is dealt with in a good degree of detail. This creates a sense of rigorous engagement and is concomitant to the recurrent primary focus of attention that the author places on the main issues.

Involving both social and musical contexts, as well as the practicalities intrinsic to photography and jazz performance, the author presents the historical development of jazz on a metaphorical continuum with the diachronic development of photography. Discourse surrounding cultural issues holds various complexities and therefore this continuum is not clearly defined, and as a result, the author shifts between various issues relating to the jazz image. In terms of dialectics the author's style of working out ideas in an extensive discourse, which settles with concluding remarks, pervades each of the chapters. At times this method of composition is slightly disconcerting, flitting as it does from one topic to another, particularly in Chapter three.

Interestingly, the author posits that the resurgence in the 1980s of public interest in classic mainstream jazz is describable as a neoclassical era, and this fresh interest in the music was paralleled by an increased demand for Herman Leonard's photographs, since they perfectly satisfied the need for visual images of jazz icons. The interlude between the time when the photographs were taken and the resurgence of interest in the music created a void. This was compounded by the fact that many of the great musicians of jazz were photographed in their prime and at the height of their musical powers and many of them were already deceased by the 1980s. Viewer gratification is also accommodated by visual representation of jazz (culture) in the 1950s, thus affording an historical affiliation with the era. The author discusses matters of categorization and development under the umbrella term 'jazz', and aligns Leonard's photography with the reification and establishment of the term 'mainstream jazz' (p. 13). These aspects are highlighted in The Jazz Image, which suggests that Leonard's aesthetic musical preference and passion for mainstream jazz is reflected in the choices of musicians whom he selected as photographic subjects.

It is possible that Leonard's photographs promoted a kind of neoclassicism through their use of iconic figures who represented classic mainstream jazz. This hypothesis is brought to its zenith with the more recent depiction of the contemporary champion of neoclassicism, Wynton Marsalis, taken in the 1990s (Figure 4.3, p. 161). Furthermore, this informs the 
reader of some of the qualities considered inherent to mainstream jazz such as the blues aesthetic, and in comparison to the bebop style the use of less complex melodic material. Bebop is not discussed as a jazz subgenre that belongs to the mainstream. Leonard has in fact also photographed bebop players and the author misses an inconsistency created by her premise that Leonard promoted the mainstream only. This is somewhat problematic due to the way in which there is a criss-crossing between some of the terms used to pigeonhole jazz musicians and their styles, and is further complicated by the fact that many jazz musicians have performed in numerous subgenres and have gone through musical changes during their careers.

Throughout this text the author broaches the issue of subjective diachronistic changes in the music and how they impacted on both audiences and performers. It is due to the advancements in jazz and postmodernist positions on neoclassicism that the author then provides an extensive discourse on the avant-garde and socio-musical issues related to that style. Matters of change are elucidated in the second part of the book since experimental jazz in the forms of the avant-garde and free jazz are discussed at length, particularly the radical experimental performance practices employed by artists such as Ornette Coleman and Muhal Richard Abrams. Attitudes, expressions and photographs of these performers provide effective case studies, examining the social and musical issues concomitant with representations of their respective iconographies. In relation to the categorization of jazz, the author states that although these performers are recognized as members of the overall jazz community, their differences were highlighted by non-acceptance and by criticism from certain sections of the larger jazz community. These experimental jazz performers were ostracized from their communities by those musicians who were imbued with a desire to maintain an AfricanAmerican heritage. Because of their non-conformity, the experimentalists were regarded as dissenters who did not show respect for the stoicism of their forefathers. Pinson highlights the problematic issues of categorization and the use of descriptive terminology and investigates how experimental jazz is represented in order to support the argument for the representation of the (classic) jazz image and its affiliation to mainstream. The terms free jazz, fusion and avant-garde are discussed at length and there is an explanation of the clever visual representation of free jazz as it has been written with a strikethrough, free jazz, which refers to Derrida's concept of erasure. Pinson states: '[T]he strikethrough attaches the word to its meaning, it also conceals other meanings ... and yes, images, that are attached to this term but do not always fit its description' (p. 149). Presented in this eye-catching manner it 
also represents the negation of the term in relation to how the musicians associated with the style perceived their own musical activities. The impact of these repeated strikethroughs as visual images within a piece of prose focuses the reader's attention on the negation.

It is quite clear throughout this text that the author is passionate about jazz and the visual image, and I get a sense that she explores her specific relationship with jazz and American culture informed by a perspective infused with social constructivist theory. Interestingly, this is brought to the fore on two counts. The first is the careful consideration of the domination of jazz performance by the male, and the second is domination of the jazz image by African-American males, both of which elucidate females in absentia. The appropriation of black music by a white community is discussed in a dialectic that covers historical work on the issues and the post-structural arguments that have ensued. Rhetoric of absence, or more precisely the lack of consideration of European jazz musicians in relation to the jazz canon and the assimilation of African-American aesthetics by others, is among the further issues that assist in establishing the power of the jazz image. Phallic symbolism in relation to the positioning of the African-American jazz musician and the consideration of the absence of the female jazz musician is considered analogous to the biological absence of a female phallus. This also affirms how the public, both experts and non-experts, can be influenced by selected visual images. Mediation of the jazz image in relation to how the subjects are framed, the composition, and how the viewer may be expected to perceive the subject, are connected issues that contribute to some of the overarching questions of this study.

The author investigates the ways in which a viewer can interpret visual messages represented in a photograph and she analyses several images by Leonard and others to support her argument. In particular she applies Barthes's conceptual theory of denoted and connoted messages. Denotation refers merely to the subject as the primary visual text and the connoted messages are contained in a secondary - though not necessarily subordinate-interpretation. Although in her conclusion the author acknowledges that there are potentially 'hundreds of interpretations' and ways to interpret the jazz image other than those provided in this book (p. 185), the actual interpretation and analysis of the Dizzy Gillespie image (Figure 1.11, p. 49) provides an interesting case. Leonard attempts to create an illusory reality in this picture with the use of backlighting to highlight a three-dimensional perspective which Pinson does not pick up on. Furthermore, the photographer as artist attempts to convey verisimilitude to the viewer, providing a

(c) Equinox Publishing Ltd 2014.

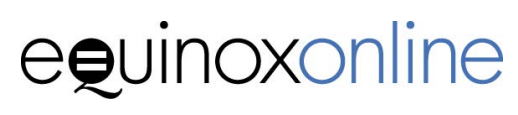


visual representation of the perceptual experience in relation to reality and the jazz icon. Perceived realness in iconography and in jazz audio-visuals can create a problematic virtual sense of intimacy in the viewing experience, which in turn can provide a sense of ownership and exclusivity for the viewer. Perhaps this is another of the reasons for Leonard's success: even though his prints were mass-produced, viewers can experience a closeness to jazz icons and to jazz culture. This again can satisfy desires on the part of the viewer to interact with the original era albeit anachronistically - in this case the classic mainstream jazz culture - through viewer gratification. Pinson states that most of Leonard's photographs captured the musicians either as they were performing or as they were about to perform and suggests that this virtual state of performance may also account for his greater fame, according him higher accolades in comparison to his peers as it played on the viewer's desire to interact with or participate in the action.

The author discusses rhythm and social dialogue, adapted from theoretical premises by Lowry and Bakhtin, which alluded to a dialogue between the viewer and the subject. Her use of descriptive language for the setting in which Leonard captured the drummer Max Roach (Figure 2.1, p. 73) is intriguing as the author incorporates pace rhythm, creating the impression of visual motion in the analysis. This perceptual motion is achieved by discussing shapes and positioning within the composition, suggesting a hierarchical order for scanning the images analogous to the panning operation of a television camera. Perhaps the author was influenced by Leonard's comments regarding mediation: 'First of all, that was a black and white age. The movies were in black and white; television was in black and white' (p. 75). Therefore the reason for his concentrated use of black-and-white film was due to the fact that it was standard practice at that time. I interpret this as an effective adoption of this theoretical approach in Pinson's writing, one that is most engaging in the analysis and in the interpretation of connoted messages. This approach can bring life to the dialogical interaction between the reader as viewer and the author as both presenter and analyst of the subject, and can increase a sense of life to the two-dimensional photograph that hinges on or is supplemented by viewer gratification. Moreover, the photographer raises the status of the object to that of an artistic creation and thus enhances the spectator's experience.

The main book title is cleverly crafted since the word 'image' is open to several possible interpretations. 'The Jazz Image' could refer to a book that deals mainly with jazz photography, but the subtitle 'Seeing Music Through Herman Leonard's Photography' provides a more exact description of the 
content, thus identifying this work as an interrogative discourse not only of the jazz image but also of the associated culture or the image of jazz.

Furthermore, the photograph that adorns the dust jacket is cleverly chosen. It depicts Wynton Marsalis holding a trumpet to his lips as if in performance mode. In relation to Barthes's concept of connoted messages this image is very powerful since it positions Marsalis as the harbinger of an important work. Marsalis, of course, is considered a pre-eminent jazz trumpeter who is also a champion of neoclassical mainstream jazz. This ties in with the specific jazz subgenre which Leonard has concentrated on, namely, classic mainstream. One of the connoted messages that Pinson has interpreted from this same image is that Marsalis is 'beaming the sound out into the air just as a lighthouse beams its own light to a wandering ship'. This is perhaps yet another reason for choosing to use this photograph on the jacket, to capture 'wandering' readers (p. 162). Admittedly, multivalence in relation to analysis has the potential to spiral ad infinitum.

It is the author's combination of visual culture with jazz culture and the musical sounds of jazz that makes this a considerable and rigorous contribution to the interdisciplinary field of media studies and jazz scholarship. Pinson opens the door for her readers to sense her own perceptions and visual gratification through theories and analyses of visual culture in frames composed by Herman Leonard. 